\title{
GAMIFICAÇÃO NO ENSINO DE ASTRONOMIA
}

\section{GAMIFICATION IN ASTRONOMY TEACHING}

\author{
Roger Broetto Rocha ${ }^{1}$ \\ Lucio Martins Fassini da Silva ${ }^{2}$ \\ Cleiton Kenup Piumbini ${ }^{3}$ \\ Luiz Otavio Buffon ${ }^{4}$ \\ Marconi Frank Barros 5
}

\begin{abstract}
Resumo: Este trabalho tem por objetivo relatar uma atividade didática, realizada no Programa Institucional de Bolsas de Iniciação à Docência (PIBID), envolvendo o ensino de Astronomia numa turma do primeiro ano do ensino médio de uma escola do município de Vitória, ES. A atividade foi planejada e executada pelo subprojeto do Curso de Licenciatura em Física do IFES - Campus Cariacica. A metodologia foi baseada na Gamificação aplicada ao ensino-aprendizagem. A intervenção ocorreu em três etapas, sendo a primeira realizada em dois encontros, através de apresentações dialogadas sobre Astronomia usando slides e gifs, a segunda consistiu na aplicação da Gamificação através de um jogo e finalizando com a terceira etapa, foi aplicado um pequeno questionário. Ao final houve um momento de avaliação e as análises constataram que o ensino de Astronomia através da atividade gamificada do jogo conseguiu motivar os alunos, despertar o interesse pelo assunto e produzir indícios de aprendizagem.
\end{abstract}

Palavras-chave: Gamificação em sala de aula; Ensino de Astronomia; PIBID.

Abstract: This work aims to report on a didactic activity, carried out in the Institutional Program for Teaching Initiation Scholarships (PIBID), involving the teaching of Astronomy in a class of the first year of high school at a school in the city of Vitória, ES. The activity was carried out by the subproject of the Physics Degree Course at IFES - Campus Cariacica. The intervention took place in three stages, the first being in two meetings, through dialogued presentations on Astronomy using slides and gifs, the second consisted of the application of Gamification through a game and ending with the third stage, a small questionnaire was applied. At the end there was a moment of evaluation and the analyzes found that the teaching of Astronomy through the gamified activity of the game managed to motivate students, arouse interest in the subject and produce evidence of learning.

${ }^{1}$ Licenciando em Física, Bolsista do PIBID - CAPES, Curso de Licenciatura em Física do Instituto Federal do Espírito Santo (IFES), Campus Cariacica, Cariacica, Espírito Santo, Brasil. rogerbroettorocha@gmail.com.

${ }^{2}$ Licenciando em Física, Bolsista do PIBID - CAPES, Curso de Licenciatura em Física do Instituto Federal do Espírito Santo (IFES), Campus Cariacica, Cariacica, Espírito Santo, Brasil. luciofassini @ gmail.com.

${ }^{3}$ Doutor em Física, Coordenador de Área do PIBID - CAPES. Núcleo de Estruturação do Ensino de Física (NEEF), Coordenadoria de Física, Mestrado em Ensino de Física, Instituto Federal do Espírito Santo (IFES), Campus Cariacica, Cariacica, Espírito Santo, Brasil. cleiton.kenup@ Ifes.edu.br.

${ }^{4}$ Doutor em Física, Coordenador de Área do PIBID - CAPES - Núcleo de Estruturação do Ensino de Física (NEEF), Coordenadoria de Física - Mestrado em Ensino de Física - Instituto Federal do Espírito Santo (IFES), Campus Cariacica, Cariacica, Espírito Santo, Brasil. buffon@ifes.edu.br.

${ }^{5}$ Mestre em Ensino de Física - Professor supervisor do PIBID - CAPES - Professor Efetivo da Rede Estadual de Ensino do Estado do Espírito Santo, Cariacica, Espírito Santo, Brasil. marconibarros05@gmail.com. 
DOI: https://doi.org/10.33238/ReBECEM.2020.v.4.n.4.26158

Keywords: Gamification activity in the classroom; Astronomy teaching; PIBID.

\section{Introdução}

Dentro das denominadas ciências naturais, a Astronomia talvez seja uma das mais antigas ciências, tendo seu desenvolvimento sido iniciado na antiguidade. Além de permitir um melhor conhecimento do Cosmos, ela tinha muitas aplicações práticas, tais como o acompanhamento das estações do ano, o conhecimento dos períodos mais apropriados para plantios, dentre outras aplicações. Os calendários atuais ainda são definidos usando-se a Astronomia. A necessidade dos estudos astronômicos também impulsionou o desenvolvimento de outras áreas do conhecimento tais como, a Matemática, a Física e o desenvolvimento de instrumentos de medição e da tecnologia em geral.

Para Brasil (2017), as Ciências Naturais, em seu conjunto, estudam diferentes fenômenos naturais e geram representações do mundo ao buscar compreensão sobre o Universo, o espaço, o tempo, a matéria, o ser humano, a vida, seus processos e transformações.

Em particular, a Astronomia é, na sua essência, a ciência de observar os astros, explicar seus movimentos, descobrir suas características e sua natureza (MOURÃO 1997). Segundo Soler e Leite (2012, p.373), os elementos relacionados à importância e às justificativas para o ensino de Astronomia podem se organizados como:

a) Despertar de sentimentos e inquietações: a Astronomia, supostamente, possuiria a característica de despertar vários tipos de sentimentos, junto a diferentes grupos sociais, tais como curiosidade, interesse, fascinação, encantamento, e esta característica poderia ser aproveitada no processo de ensino-aprendizagem de temas e conteúdos ligados a ela;

b) Relevância sócio-histórico-cultural: a Astronomia teria uma significativa relevância sócio-histórico-cultural, pois, ao longo da história humana, o seu desenvolvimento teria proporcionado diversas contribuições para a evolução de civilizações, tais como possibilidade de registro e organização do tempo, aprimoramento nas técnicas de plantio e caça, orientação necessária para grandes locomoções, dentre outras;

c) Ampliação da visão de mundo e conscientização: o estudo e o aprendizado de conhecimentos da Astronomia poderiam promover ampliação de visão de mundo, questionamentos e reflexões, o que também poderia acarretar numa maior conscientização a respeito de temas como cidadania, preservação ambiental e sustentabilidade;

d) Interdisciplinaridade: a Astronomia teria a característica de facilmente se relacionar com outras áreas do conhecimento humano, o que constituiria um grande potencial educativo. 
DOI: https://doi.org/10.33238/ReBECEM.2020.v.4.n.4.26158

As dificuldades no ensino da Astronomia no Brasil vêm sendo estudadas por diversos autores, dentre eles, Bisch (1998), Leite (2002) e Langhi (2014). Algumas dificuldades estão relacionadas ao despreparo dos professores e uso de livros didáticos inadequados, conforme ressaltado abaixo:

Esse professor pouco sabe sobre os conceitos científicos envolvidos nos
estudos sobre as estrelas, galáxias, o universo, ou até mesmo sobre o Sistema
Solar, pois em sua formação conhecimentos dessa natureza não fizeram parte
do currículo escolar. Já o livro didático do ensino fundamental, que
normalmente é fonte de conhecimento para ele, apresenta os conteúdos
fragmentados, pouco profundos, quando não errôneos, e, ainda, insuficientes
para a explicação das muitas questões veiculadas pelos meios de comunicação
(LEITE, 2002, p.1).

Apesar da citação se referir ao ensino fundamental, acredita-se que um problema semelhante ocorra no ensino médio. Assim, se justifica que programas de formação de professores nas licenciaturas em Física, tais como os projetos PIBID e Residência pedagógica, trabalhem com o ensino de Astronomia juntos aos licenciandos.

Uma vez que a necessidade do estudo da Astronomia no ensino médio esteja bem fundamentada, é importante escolher uma metodologia que torne o seu ensino mais lúdico e prazeroso. Uma possibilidade para isso é trabalhar com Gamificação, que consiste em introduzir atividades pontuadas gerando uma competição benéfica na sala de aula, para motivar e dinamizar o processo de ensino. De acordo com Deterding (2011, p.1 apud PAGANINI, 2018, p. 21):

[...] "gamificação": o uso de elementos de game design em contextos de não game. Isso é feito para gerar "engajamento de usuários", ou seja, para motivar os usuários a envolver-se com um aplicativo ou serviço, geralmente tornandoo mais "divertido" de usar.

Deterding (2011 apud PAGANINI, 2018) defende utilizar as estratégias já testadas dos jogos digitais em outros contextos, como por exemplo o educacional. Nessa linha:

\begin{abstract}
Se por um lado, a gamificação é capaz de envolver o aluno na resolução de problemas reais, ajudando-o a dar significado para aquilo que estuda, de outro possibilita que o professor elabore estratégias de ensino mais sintonizadas com as demandas dos alunos, apropriando-se da linguagem e estética utilizada nos games para construir espaços de aprendizagem mais prazerosos. (ALVES; MINHO; DINIZ, 2014, p.90).
\end{abstract}

As atividades gamificadas permitem apresentar um problema real aos alunos no sentido de que eles têm a missão de solucioná-lo para conseguir as pontuações, isto é, eles têm uma tarefa objetiva a ser cumprida. Através da gamificação, o professor pode 
DOI: https://doi.org/10.33238/ReBECEM.2020.v.4.n.4.26158

tornar o ensino mais prazerozo, atendendo a demanda dos alunos de que a aula seja mais agradável.

Diante disso, neste presente trabalho, utilizou-se a gamificação no estudo da Astronomia, aproveitando os elementos dos games (procedimentos, estratégias, pensamentos e atitudes) para promover a aprendizagem (LÉVY, 2009; KAPP, 2012). Para Almeida (1974, p. 32), os jogos didáticos sob o aspecto mental:

[...] visam atingir o desenvolvimento da memória, da atenção, da observação, do raciocínio, da criatividade, da aquisição de hábitos ou virtudes morais, como lealdade, a bondade. Sob o ponto de vista social, os jogos visam a estimular o companheirismo, desenvolver o espírito de cooperação, o senso social e a democratização.

Portando, se acredita que a combinação do ensino de Astronomia, utilizando atividades lúdicas baseada em jogos, pode ser uma boa alternativa, já que pode-se abordar conteúdos de forma divertida e dinâmica, buscando-se atingir algumas das competências citadas acima em Almeida (1974, p. 32).

Assim, o objetivo geral da intervenção didática relatada neste presente artigo foi desenvolver uma atividade gamificada para o ensino de Astronomia. A pergunta que este artigo pretende responder é: É possível ensinar Astronomia no ensino médio, associada com uma atividade gamificada de um jogo de cartas, de forma a conseguir despertar o interesse, a curiosidade e a fascinação dos alunos, ampliando suas visões de mundo e os conscientizando da importância do tema para a sociedade?

Para isso os objetivos específicos da intervenção didática foram:

- Apresentar o conteúdo de Astronomia de forma dialogada e priorizando as curiosidades;

- Construir um jogo de cartas baseado no jogo "passa ou repassa" e testar com os alunos;

- Preparar e aplicar a sequência didática gamificada, coletar informações sobre essa aplicação e analisar se houve indícios de aprendizagem.

Nas próximas seções serão apresentadas a metodologia utilizada, a descrição da sequência didática construída, o relato dos encontros com os alunos, os dados coletados e as análises dos resultados. Por fim, na última seção, são apresentadas as conclusões. 


\section{Metodologia}

Essa atividade foi desenvolvida e aplicada no subprojeto do PIBIB - CAPES (Programa Institucional de Bolsa de Iniciação à Docência) do Curso de Licenciatura em Física do IFES - Campus Cariacica. A metodologia empregada teve como base aulas expositivas dialogadas, com uso de mecanismos de contextualização e interação, em conjunto com um jogo de cartas que abordou o conteúdo de Astronomia. A seguir, serão apresentados o planejamento da proposta didática e as regras de funcionamento do jogo.

\subsection{A proposta didática}

Os sujeitos da pesquisa foram 20 alunos do primeiro ano do ensino médio de uma escola estadual localizada no Centro de Vitória, ES. No quadro 1, a seguir, apresentamos de forma resumida os encontros da sequência didática construída, onde cada encontro corresponde a uma aula de 55 minutos.

Nos dois primeiros encontros foi apresentado o projeto para a turma e também discutido o conteúdo específico de Astronomia. Procurou-se priorizar as discussões mediadas por slides e gifs ${ }^{6}$ envolvendo curiosidades sobre o assunto. Visto que a Astronomia é pouco abordada nas aulas do ensino médio, foram reservados dois encontros para que a apresentação fosse mais gradual e sem a concentração de muita informação num só dia. Nesses $1^{\circ}$ e $2^{\circ}$ encontros foram usadas as seguintes problematizações junto aos alunos promovendo diálogos:

- As estrelas são todas iguais? O que as diferencia?

- Como que a luz do Sol chega até a Terra? Isso leva algum tempo?

- Qual a forma da Terra? Ela é uma esfera perfeita?

- Quais as diferenças entre os planetas Júpiter e a Terra? Qual seria seu peso lá?

- Nós estamos sozinhos no Universo?

\footnotetext{
6 Os slides e gifs utilizados nessa exposição podem ser vistos em: https://docs.google.com/presentation/d/1JXXqttQaezGc68A3pwew0pQS0CL--

XTm6ScWUzsowrg/edit\#slide=id.g59f3769b88_0_39 ou

ou em

https://drive.google.com/file/d/1f1EXk8nXDxwbfSfNPAGTHGn3Xh0sQteN/view?usp=sharing.
} 
DOI: https://doi.org/10.33238/ReBECEM.2020.v.4.n.4.26158

\begin{tabular}{|l|l|l|}
\hline Encontros & Atividades & Tempo \\
\hline $\begin{array}{l}1^{\circ} \text { Encontro } \\
10 / 05 / 2019\end{array}$ & $\begin{array}{l}\text { Apresentação do projeto. } \\
\text { Parte 1 da aplicação do conteúdo através de aula dialogada } \\
\text { problematizando a Astronomia }\end{array}$ & 55 minutos \\
\hline $\begin{array}{l}2^{\circ} \text { Encontro } \\
14 / 05 / 2019\end{array}$ & $\begin{array}{l}\text { Parte } 2 \text { da aplicação do conteúdo através de aula dialogada } \\
\text { problematizando a Astronomia }\end{array}$ & 55 minutos \\
\hline $\begin{array}{l}3^{\circ} \text { Encontro } \\
31 / 05 / 2019\end{array}$ & Aplicação do jogo & 55 minutos \\
\hline $\begin{array}{l}4^{\circ} \text { Encontro } \\
18 / 06 / 2019\end{array}$ & Aplicação do questionário individual & 55 minutos \\
\hline
\end{tabular}

Quadro 1: Quadro-resumo da proposta didática

Fonte: Elaborado pelos autores

No terceiro encontro foi aplicado na turma, dividida em dois grupos, a atividade gamificada que consistiu num jogo de cartas de perguntas e respostas, no estilo "Responde ou Passa", denominado de "Curiosidades da Astronomia", cujas regras serão descritas na próxima subseção. Este jogo foi criado baseado no jogo descrito por Miranda et al. (2016) e no Portal Blogspot (2013).

Por fim, no quarto encontro foi aplicado um questionário de 3 perguntas abertas para verificar o aprendizado gerado pela intervenção e a opinião dos alunos a respeito da intervenção. Na seção 3 apresentaremos o relato de como ocorreram essas atividades.

\subsection{O Jogo "Curiosidades da Astronomia"}

Consiste num jogo de baralho de 43 cartas (ver figura 1), 2 dados e 1 cronômetro ou celular para marcar o tempo. Cada carta contém uma pergunta e três opções de respostas. As cartas ${ }^{7}$ estão divididas em dois grupos, sendo 26 cartas com “valor \pm 1 ” e 17 com "valor \pm 3 ". A seguir, serão descritas em detalhes as regras e o roteiro de aplicação do jogo.

\section{Regras do Jogo:}

1. Devem existir duas equipes, cada uma com um nome. A quantidade de componentes em cada equipe deve ser a mesma ou próxima.

\footnotetext{
7 Todas as cartas com as perguntas e respostas podem vistas em https://docs.google.com/presentation/d/1wdYF1wA1RaQlnYVagNo_HIPX3qtYw8wMwcg6c8COkE/edit?usp=sharing ou https://drive.google.com/file/d/1EEluc21Nhr6_gOCw63uuZBAJQfNkgmEi/view.
} 


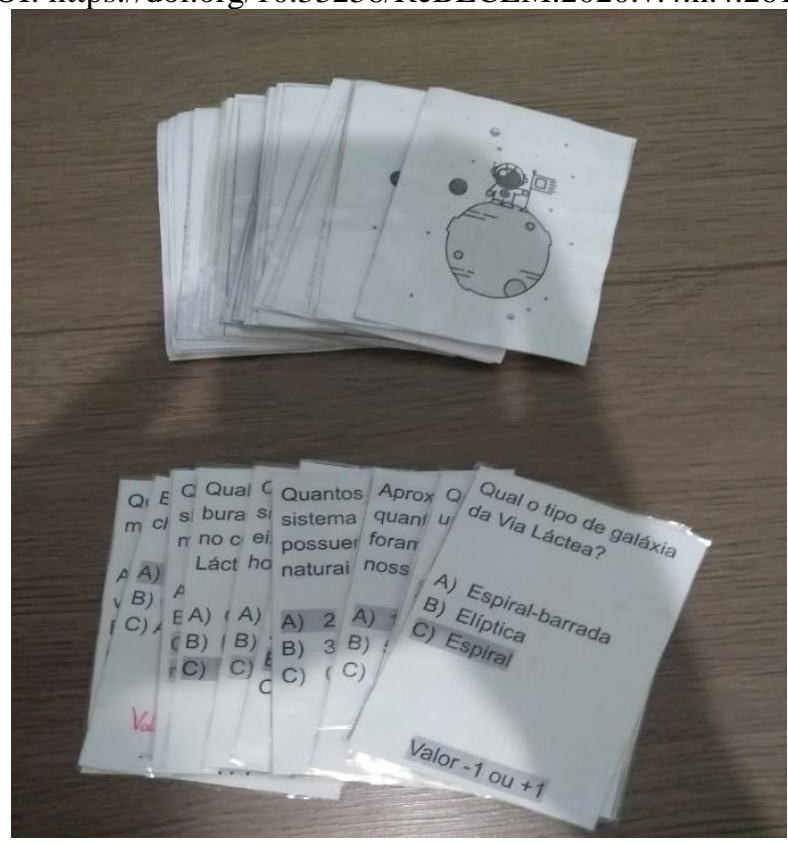

Figura 1: Foto do jogo de cartas

Fonte: Acervo dos autores

2. Uma pessoa ficará com o papel de juiz, sendo responsável pelas cartas e por contabilizar os pontos.

3. Cada equipe recebe um dado, que será usado para determinar quem inicia a rodada.

4. A cada rodada os jogadores devem ser trocados. Independente da rodada anterior, os jogadores devem jogar os dados para determinar quem tem o direito de tentar responder primeiro e isso deve ser feito em todas as rodadas.

5. Um jogador só poderá voltar a jogar depois que todos os outros do time tenham jogado.

6. O jogador que inicia a rodada terá que responder uma pergunta, ou se preferir, passar a vez para o adversário, que por sua vez poderá responder ou repassar a vez para o jogador que tinha iniciado a rodada, sendo este obrigado a responder à pergunta. $\mathrm{O}$ tempo de resposta deverá ser de no máximo 30s e sempre de forma individual.

7. As cartas contendo as perguntas que forem respondidas de forma correta devem ser descartadas e as respondidas de forma errada devem voltar para a pilha de cartas.

8. Cada carta possui um valor escrito na parte inferior. No caso de o participante acertar ele irá receber essa pontuação, caso contrário irá perder esse valor dos pontos existentes. Assim, o placar de pontos pode vir a ser composto por valores negativos. Por exemplo: Grupo 1 com -10 pontos e Grupo 2 com -2 pontos. 


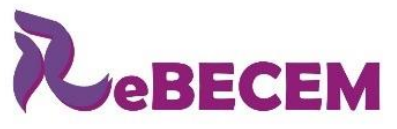

\section{Revista Brasileira de Educação em \\ Ciências e Educação Matemática \\ ISSN 2594-9179}

DOI: https://doi.org/10.33238/ReBECEM.2020.v.4.n.4.26158

9. O time vencedor será aquele que possuir o maior valor de pontos. No exemplo do item 8 acima, o grupo 2 seria o vencedor pois $-2>-10$.

\section{Roteiro para a aplicação do jogo.}

1. Se possível organizar uma mesa com duas cadeiras, como a da foto da figura 2 , que usamos nessa pesquisa.

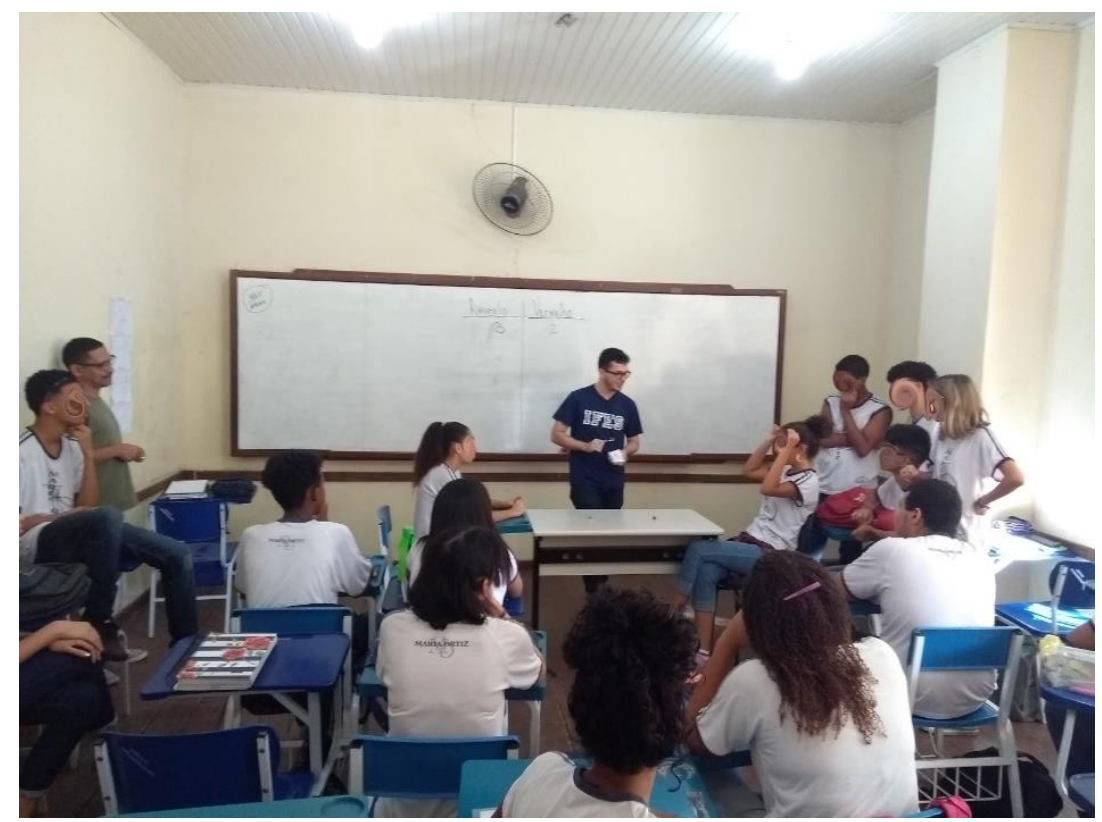

Figura 2: Foto da aplicação do jogo no $3^{\circ}$ encontro.

Fonte: Acervo dos autores

2. A pontuação deve ser escrita no quadro ou em algum local onde todos os jogadores tenham noção de como está a pontuação dos grupos.

3. As regras do jogo devem ser explicadas para a turma, esclarecendo possíveis dúvidas.

4. Deve ser decidido se o juiz será um aluno ou o próprio professor/responsável.

5. A Turma/Sala deve se dividir em dois grupos, com o número aproximado de integrantes. As equipes são livres para escolher um nome para o time, deve se tomar cuidado com os nomes inapropriados.

6. Cada grupo deve se organizar e achar uma sequência em que cada aluno irá participar. Assim, cada aluno consequentemente terá um "oponente” fixo.

OBS: Uma outra sugestão, seria o professor ir escolhendo cada aluno de cada grupo por rodada, de forma aleatória.

7. Decidido quem será o primeiro a jogar, os mesmos devem ir para as cadeiras onde irão jogar os dados para decidir quem começa. 
DOI: https://doi.org/10.33238/ReBECEM.2020.v.4.n.4.26158

8. O professor pode optar por explicar as perguntas que forem respondidas de forma errada, porém essas perguntas (cartas) devem ser descartadas.

9. A escolha do prêmio será feita pelo professor.

A seguir, serão apresentadas as informações coletadas bem como as análises dos resultados.

\section{Análise dos resultados}

Nessa seção serão apresentados os relatos dos encontros bem como uma análise do questionário aplicado e dos resultados obtidos. Dos 20 alunos da turma 15 participaram ativamente do jogo e 19 responderam o questionário final.

\subsection{Relato do primeiro encontro:}

Por ser o primeiro, este encontro iniciou com a apresentação do projeto do PIBID aos alunos. Em seguida, foi abordado o assunto "Estrelas" e suas diferenciações em classes e isso causou surpresa e interesse nos alunos, pois era algo que eles não conheciam. Alguns questionamentos e dúvidas logo surgiram em relação ao assunto, como por exemplo, um aluno achava que a luz do Sol chegava na Terra instantaneamente. Outro momento que chamou atenção, foi a apresentação da real forma da Terra através de um gifs, pois a maioria dos alunos achavam que a Terra era perfeitamente esférica.

O interesse pelo assunto se manteve alto durante toda a aula, como por exemplo, na apresentação sobre o planeta Júpiter, onde muitos alunos ficaram admirados pelo fato do planeta ser muito grande quando comparado com a Terra. A massa e o volume de Júpiter são cerca de 318 e 1321 vezes os valores dessas grandezas da Terra, respectivamente. Sua enorme quantidade de 79 satélites naturais também impressionou os alunos. Inclusive, algumas dúvidas surgiram nesse momento da aula, como por exemplo, se nós tínhamos conhecimento de qual seria a gravidade em Júpiter e de como ela poderia ser calculada.

\subsection{Relato do segundo encontro:}




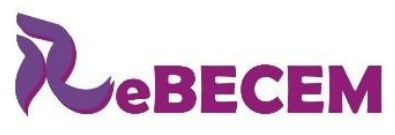

DOI: https://doi.org/10.33238/ReBECEM.2020.v.4.n.4.26158
Revista Brasileira de Educação em

Ciências e Educação Matemática

ISSN 2594-9179

No segundo encontro, foi revisado de forma rápida o que foi falado no primeiro e então foi retomado o assunto abordando algumas curiosidades sobre a Via Láctea. Nesse encontro, a aula foi totalmente descontraída, pois, cada assunto exposto, causava surpresas ou espantos e também dúvidas. Isso deixou a aula bem participativa, com vários alunos dando suas opiniões a respeito dos questionamentos feitos. Para finalizar, foi perguntado para os alunos se "Nós estamos sozinhos no Universo?", para criar um pequeno debate entre eles e deixar a aula ainda mais participativa. Pôde-se constatar que se colocando perguntas de interesse dos alunos é possível torná-los mais participativos e fazer com que dialoguem mais entre eles e com o professor.

Assim que foi encerrado os assuntos discutidos, foi perguntado para os mesmos o que acharam da aula e foi feito o esclarecimento de dúvidas. De forma unânime, os alunos aprovaram a aula, e ainda foi pedido para terem mais aulas desse modelo, e que se possível, fosse aplicado por nós novamente, pois gostaram do tom descontraído da aula apresentada.

No final do segundo encontro, foi falado que no próximo encontro seria trabalhado um jogo chamado "Curiosidades da Astronomia", e que nesse jogo iria ter algumas curiosidades além das que foram apresentadas em forma de perguntas, onde o grupo ganhador receberia um prêmio.

\subsection{Relato do terceiro encontro:}

Nesse encontro, foi trabalhado o jogo "Curiosidades da Astronomia". Inicialmente, foi perguntado à turma se eles ainda lembravam das informações apresentadas nos dois primeiros encontros ou se tinham pesquisado algo além do que foi apresentado nos slides. Então, em seguida, foi falado do jogo, explicando suas regras, como seria jogado e o prêmio que o time vencedor iria receber. O prêmio escolhido foi duas caixas de "Bis".

Durante a separação e organização dos grupos, percebeu-se uma certa "bagunça", mas considerada normal, tendo em vista que a interação com o conteúdo se daria de uma forma diferente da que eles estavam acostumados. A turma se dividiu em um time amarelo e um time vermelho, e assim foi iniciada a primeira rodada.

Optou-se por realizar breves comentários sobre algumas perguntas que foram respondidas incorretamente e quando necessário também tecendo alguns comentários sobre as respondidas corretamente, em alguns casos em que o acerto pareceu ser 


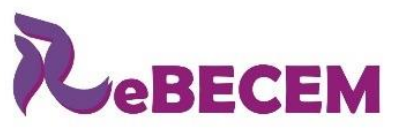

Revista Brasileira de Educação em

Ciências e Educação Matemática

DOI: https://doi.org/10.33238/ReBECEM.2020.v.4.n.4.26158

proveniente de um "chute". Essas intervenções foram feitas para aproveitar o momento de interesse dos alunos e completar o ensinamento do conteúdo.

A existência de uma premiação para o time vencedor, trouxe um sentimento saudável de competitividade à turma, o que até certo ponto era buscado, já que motivaria a turma a tentar vencer e possivelmente a uma melhor imersão no jogo. Entretanto, cerca de 5 alunos não quiseram continuar participando ativamente do jogo, sendo talvez o motivo, o receio de serem repreendidas pelo time ao errarem as perguntas. Após a primeira rodada geral onde todos jogaram uma vez cada, decidiu-se por deixar os alunos mudarem a ordem dos jogadores do jeito que achassem melhor, lembrando apenas que um jogador só poderia voltar a jogar após 3 rodadas.

O jogo foi finalizado entre 5 a 10 minutos antes do término da aula, tendo como time vencedor o "vermelho" com -10 pontos. O tempo restante foi usado para conversar com os alunos, sobre o que eles acharam da interação e explicar que seria aplicado um questionário num próximo encontro.

Percebeu-se uma certa dificuldade dos alunos em responder as respostas de forma correta, o que pode ser constatado nas pontuações negativas do resultado, pois no placar final a equipe Vermelha pontuou negativamente em (-10 pontos) e a equipe Amarelo pontuou em (-15 pontos).

\subsection{Análise do questionário do quarto encontro}

Após a aplicação do questionário individual feita no quarto encontro, eles foram recolhidos para uma minuciosa análise. Foi feito um levantamento das respostas em cada questão para cada aluno e aqui serão relatadas e analisadas uma questão de cada vez.

Questão 1: "Segundo o que foi trabalhado em Astronomia, o que caracteriza uma estrela?"

Objetivo da questão: Verificar se o aluno conhece as propriedades que caracterizam uma estrela tais como: massa, cor, luminosidade, temperatura, composição e idade.

O desempenho dos alunos nas respostas dessa questão foi analisado dentro da metodologia da Análise de Conteúdo (MORAES, 1999) e classificado em três categorias:

- Desempenho Máximo: Foi atribuído ao aluno que soube desenvolver os conceitos relacionados a resposta, mostrando que pode caracterizar uma estrela com 
DOI: https://doi.org/10.33238/ReBECEM.2020.v.4.n.4.26158

coerência. Segue um exemplo de resposta correspondentes a um desempenho máximo: "Seu nível de energia, cor, luminosidade, tempo de vida e características gerais em si."

- Desempenho Intermediário: Foi atribuído ao aluno que ficou entre o máximo e o mínimo. Segue um exemplo de resposta correspondentes a um desempenho intermediário: " O que caracteriza uma estrela, é a quantidade de brilho que ela tem. Por exemplo o sol é a estrela que tem mais brilho."

- Desempenho Mínimo: Foi atribuído ao aluno que não soube desenvolver os conceitos relacionados a resposta, mostrando ser incapaz de caracterizar uma estrela com coerência. Segue um exemplo de resposta correspondentes a um desempenho mínimo: "Na minha opinião caracteriza-se como um ser muito iluminado."

$\mathrm{O}$ assunto dessa questão 1 foi abordado no primeiro e segundo encontros e também no jogo no terceiro encontro. Tivemos 19 alunos respondendo essa questão $1 \mathrm{e}$ após a análise e classificação das respostas o resultado foi:

- Desempenho Máximo: 7 alunos;

- Desempenho Intermediário: 5 alunos;

- Desempenho Mínimo: 7 alunos

Assim, cerca de um terço da turma conseguiu responder a questão corretamente e no total quase dois terço apresentaram indícios de aprendizado com desempenho máximo ou intermediário.

Questão 2: "O que o jogo mudou na sua percepção sobre Astronomia?”

Objetivo da questão: Verificar se a metodologia usada, baseada no jogo e na gamificação, alterou de forma significativa a percepção dos alunos quanto ao tema da Astronomia.

Nessa questão a maioria respondeu que sim, no sentido de que o jogo mudou a percepção de cada aluno quanto à Astronomia, mas poucos explicaram exatamente o que mudou ou porque mudou. De qualquer forma, podemos ter indícios de que o jogo alterou a percepção deles dessa disciplina. A seguir, são apresentadas algumas respostas completas revelando quais foram as percepções deles:

Aluno A1: "Sim, eu pensei que astronomia era chato é que só estudava a terra é o sol, mas não, ela estuda o universo como todo, cada detalhe dos planetas e o universo. Esse conteúdo sobre Astronomia criou em mim uma curiosidade sobre os planetas, as estrelas e o universo, que antes eu não tinha. ", 
DOI: https://doi.org/10.33238/ReBECEM.2020.v.4.n.4.26158

Aluno A2: "mudou o fato de saber que existe muito mais do que vemos a olho nu no universo!"

É possível identificar nessas respostas acima o desenvolvimento de características destacadas por Soler e Leite (2012, p.373), com relação aos itens (a) de despertar a curiosidade e interesse pelo tema e (d) de ampliação da visão de mundo quanto ao campo de estudo da Astronomia, ambos citados na referência.

Aluno A3: "Achava a astronomia um assunto dificil. Agora acho compreensivel por causa do jogo e o jogo também incentiva a pesquisa sobre o assunto."

Aluno A4: "Bem, O jogo tornou para mim a astronomia um pouco mais interessante e divertido de aprender, atiça a curiosidade estudar o que há pelo universo."

Pelos comentários acima pode-se notar que o jogo melhorou a motivação e despertou algum interesse dos alunos para estudar a Astronomia. Assim, a atividade gamificada melhorou a dinâmica do ensino indo de encontro à fala citada em Deterding (2011, p.1 apud PAGANINI, 2018, p. 21) citata nesse artigo.

Questão 3: "Na sua opinião a forma como foi apresentado e trabalhado o conteúdo, fez com que você compreendesse melhor o assunto? Independente de sua resposta, cite algo que lhe chamou a atenção sobre o assunto. "Objetivo da questão: Investigar se para o aluno, a forma como foi desenvolvida a intervenção resultou numa melhor compreensão do assunto e também identificar os pontos que mais chamaram a atenção sobre o tema.

A seguir, são apresentadas algumas respostas completas revelando quais foram as percepções deles:

Aluno A5: "Me deu conhecimento e um senso maior de universo e de existencia, sobre como somos quase nada de um ponto de vista mais amplo."

Aluno A6: "Muito, foi muito interessante e bem legal, o que me chamou atenção foi toda a vida de uma estrela, desde o nascimento até sua morte".

Aluno A7: "Sim algo que me chamou atenção foi inúmeras estrelas e planetas que ainda não tem nome."

Ao observar as respostas, percebe-se que na opinião dos alunos a intervenção ajudou a compreender melhor o assunto e que eles gostaram da forma como o assunto foi desenvolvido.

A partir dos resultados da intervenção foi possível identificar o desenvolvimento de algumas habilidades citadas por Almeida (1974, p. 32), que podem ser atingidas através dos jogos, tais como o desenvolvimento da memória, da atenção e do raciocínio, 


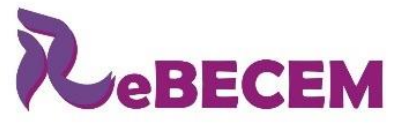

DOI: https://doi.org/10.33238/ReBECEM.2020.v.4.n.4.26158

durante o jogo de perguntas e respostas, do respeito às regras do jogo durante as competições, além de hábitos de companherismo, lealdade e honestidade entre as equipes durante o jogo.

\section{Considerações finais}

Por meio de uma intervenção usando a gamificação através de um jogo de cartas, procurou-se levar ao aluno uma diferente forma de compreensão da Astronomia. A ideia de abordar a Astronomia num jogo de perguntas mostrou-se proveitosa e bem recebida pela turma, pois através dessa "dinâmica" foi possível revisar e tirar dúvidas sobre a matéria. Durante a exposição percebeu-se grande empolgação, participação e interesse dos alunos, visto que, houve muitas perguntas relacionadas a curiosidades sobre o tema. Em conversas com a turma, ao final do segundo encontro, foi constatado a aprovação unânime da metodologia expositiva dialogada utilizada. Essas percepções de que o jogo facilitou a aprendizagem foram confirmadas nos relatos dos alunos A3 e A4 citados na seção anterior.

As aulas dialogadas, que antecederam o jogo, tentaram incentivar um processo mais democrático de ensino com mais participação ativa dos alunos, embora isso tenha ocorrido de forma incipiente. A respeito dos jogos didáticos, dentre as habilidades citadas por Almeida (1974, p. 32), houve um engajamento da maioria dos alunos reforçando a importância social da educação, o companheirismo e o espírito de cooperação. Contudo devido a natureza do jogo de perguntas e respostas não houve ênfase no desenvolvimento das habilidades da criatividade e do raciocício.

Após a intervenção ocorreu a aplicação do questionário, onde a turma mostrou um bom desempenho e ficou evidente que tal abordagem incentiva os alunos a pesquisar e estudar mais sobre o tema, tornando a ideia e a aplicação satisfatória. Os resultados do questionário, principalmente da questão 1 confirmam indícios de aprendizagem por parte dos alunos. Nessa questão, 12 dos 19 alunos responderam de forma satisfatória (desempenho máximo) ou parcialmente satisfatória (desempenho intermediário). A questão 1 , referente à vida de um estrela, permitiu mostrar o caráter interdisciplinar da Astronomia, pois envolveu grandezas da Física (massa, tempo, luminosidade e Temperatura), propriedades da Química (cor e composição química) e a matemática 


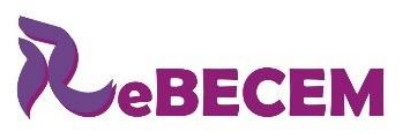

Revista Brasileira de Educação em

Ciências e Educação Matemática

DOI: https://doi.org/10.33238/ReBECEM.2020.v.4.n.4.26158

relacionada a essas ciências. Nos debates houve também menção à Biologia com a discussão se estamos sós no Universo.

Em relação à segunda pergunta do questionário, as quatro respostas relatadas neste artigo indicaram uma grande satisfação de terem aprendido um pouco mais sobre a Astronomia, além dos conhecimentos básicos sobre a Terra, o Sol e a Lua. Percebemos uma ampliação do conhecimento da turma em relação ao restante do Universo. Essa percepção foi confirmada nas três respostas apresentadas da questão 3 pelos alunos A5, A6 e A7, e isso vai de encontro com o que Soler e Leite (2012, p.373) afirmaram sobre Astronomia ser capaz “[ ... de despertar vários tipos de sentimentos, junto a diferentes grupos sociais, tais como curiosidade, interesse, fascinação, encantamento, ...]”. As respostas de dois alunos (A1 e A2), "eu pensei que astronomia era chato é que só estudava a terra é o sol, mas não, ela estuda o universo como todo" e "Me deu conhecimento e um senso maior de universo e de existencia, sobre como somos quase nada de um ponto de vista mais amplo", ilustraram também a ampliação da visão de mundo que a Astronomia permite. Em outras respostas encontramos expressões do tipo "curiosidade", "saber que existe muito mais do que vemos a olho nu no universo", revelando de certa forma um despertar da importância da Astronomia.

Assim, a associação da Astronomia com um jogo de caráter competitivo, se concretizou como uma boa forma de tirar o aluno da situação passiva, levando-o a uma maior motivação, cooperação e interação com o professor e com seus colegas de classe. Mas, deve-se sempre levar em consideração que antes de aplicar a atividade é preciso verificar se os alunos já possuem algum o conhecimento prévio do conteúdo e caso não o tenham deve-se organizar encontros anteriores para estudar esse conteúdo como foi feito neste trabalho no caso da Astronomia.

\section{Agradecimentos}

Agradecemos ao Instituto Federal de Educação, Ciência e Tecnologia do Espírito Santo (IFES), Campus Cariacica, pela oportunidade de participarmos do Programa Institucional de Bolsas de Iniciação à Docência (PIBID) e à CAPES por financiá-lo.

\section{Referências}


DOI: https://doi.org/10.33238/ReBECEM.2020.v.4.n.4.26158

ALMEIDA, P. N. Dinâmica lúdica: técnicas e jogos pedagógicos. São Paulo: Editora Loyola, 1974.

ALVES, L. R. G.; MINHO, M. R. S.; DINIZ, M. V. C. Gamificação: Diálogos com a educação. In: FADEL, L. M.; ULBRICHT, V. R.; BATISTA, C.; VANZIN, T. (Org.). Gamificação na educação. São Paulo: Pimenta Cultural, 2014. p. 74 - 97.

BISCH, S. M. Astronomia no ensino fundamental: natureza e conteúdo do conhecimento de estudantes e professores. 1998. 301f. Tese (Doutorado em Educação) - Faculdade de Educação, Universidade de São Paulo, São Paulo, 1998.

BRASIL, Ministério da Educação. Base Nacional Comum Curricular (BNCC). 2017. Disponível

em:<http://portal.mec.gov.br/index.php?option=com_docman\&view=download\&alias $=85121$ bncc-ensino-medio\&category_slug=abril-2018-pdf\&Itemid=30192>. Acesso em: 7 de maio de 2020.

KAPP, K. M. The gamification of learning and instruction: game-based methods and strategies for training and education. San Francisco: Pfeiffer, 2012.

LANGHI, R. Justificativas para o ensino de Astronomia: o que dizem os pesquisadores brasileiros? Revista Brasileira de Pesquisa em Educação em Ciências. Belo Horizonte, v. 14, n. 3, p. 41-59, 2014.

LEITE, C. Os professores de Ciências e suas formas de pensar a Astronomia. 2002. 160 f. Dissertação (Mestrado em Educação) - Instituto de Física e Faculdade de Educação, Universidade de São Paulo, São Paulo, 2002.

LÉVY, Pierre. Cibercultura. Tradução de Carlos Irineu da Costa. São Paulo: Editora 34, 2009.

MIRANDA, J.C.; GONZAGA, R.C.; COSTA, R.C.; FREITAS, C.C.C.; CÔRTES, K.C. Jogos didáticos para o ensino de Astronomia no Ensino Fundamental. Scientia plena. São Cristóvão SE, v. 12, n. 2, p. 1-11, 2016. Disponível em:

<https://www.scientiaplena.org.br/sp/article/view/2742>. Acesso em 26 ago. 2020.

MORAES, Roque. Análise de conteúdo. Revista Educação.Porto Alegre, v. 22, n. 37, p. 7-32, 1999.

MOURÃO, Ronaldo Rogério de Freitas. Da terra às galáxias: uma introdução à astrofísica. Petrópolis, RJ: Ed. Vozes, 1997.

PAGANINI, E. R. A máquina: uma proposta de livro-jogo para o ensino de eletrodinâmica básica. 2018. 233 f. Dissertação (Mestrado Profissional em Ensino de Física) - Instituto Federal do Espírito Santo - Campus Cariacica, Cariacica, 2018. Acesso 26 de agosto de 2020, 
DOI: https://doi.org/10.33238/ReBECEM.2020.v.4.n.4.26158

https://sucupira.capes.gov.br/sucupira/public/consultas/coleta/trabalhoConclusao/viewTrabalho Conclusao.jsf?popup=true\&id_trabalho=6380234.

PORTAL BLOGSPOT. Jogando aprendendo ensinando. 2013. Disponível em:

<http://jogandoaprendendoensinando.blogspot.com.br/2013/11/passa-ou-repassa.html >. Acesso em 7 de maio de 2020.

SOLER, D. R.; LEITE, C. Importância e justificativas para o ensino de astronomia: um olhar para as pesquisas da área. In: SIMPÓSIO NACIONAL DE EDUCAÇÃO EM ASTRONOMIA, II, 2012, São Paulo. Cadernos de resumos... São Paulo: Universidade de São Paulo, 2012. p. 370-379. Disponível em: <https://www.sab-astro.org.br/eventos/snea/iisnea/atas/comunicacoes-orais/ co21/>. Acesso em 26 agos. 2020.

Recebido em: 26 de outubro de 2020

Aceito em: 08 de dezembro de 2020 